\title{
Prospective Memory: The Influence of Ecstasy, Cannabis and Nicotine Use and the WWW
}

\author{
Jacqui Rodgers ${ }^{*}, 1$, Tom Buchanan ${ }^{2}$, Andrew B. Scholey ${ }^{3}$, Thomas M. Heffernan ${ }^{4}$, Jonathan Ling ${ }^{5}$ \\ and Andrew C. Parrott ${ }^{6}$
}

${ }^{I}$ Newcastle University, UK

${ }^{2}$ University of Westminster, $U K$

${ }^{3}$ SwinburneUniversity, Australia

${ }^{4}$ University of Northumbria, $U K$

${ }^{5}$ University of Sunderland, UK

${ }^{6}$ University of Swansea, $U K$

Keywords: MDMA, 'ecstasy’, memory, cannabis, nicotine, WWW.

\section{INTRODUCTION}

The aim of this investigation was to extend our previous work and establish whether the findings reported previously [1-3] of self reports of memory difficulties associated with ecstasy use can be replicated. A web-based methodology was adopted due to the significant advantages such techniques may confer when trying to reach a specialized population or address questions that people might be reluctant to answer (e.g. pertaining to illegal drug use) using traditional research methods [2, 4]. We investigated factors which may contribute to self-rated memory problems in ecstasy users.

\section{METHODS}

Four hundred and sixteen participants met our inclusion criteria. Of these, $250(60 \%)$ were female. The modal age group was $16-20$ years $(43.2 \%)$. The majority of respondents (289, 69.3\%) came from Europe. Most were educated beyond high school level $(307,73.6 \%)$. Of the people who answered the question about ecstasy use $209(50.2 \%)$ had used ecstasy on at least one occasion. Of the participants, 130 were recruited via an ecstasy-related bulletin board. We followed the same procedures as described in our earlier WWW investigation [2]. Data collection was via the WWW. Prospective memory (PM) was assessed using the Prospective Memory Questionnaire (PMQ) [5]. Drug use was assessed using a version of the UEL Recreational Drug Use Questionnaire [6] which asks respondents to estimate their level of use of ecstasy, amphetamines, cocaine, LSD, barbiturates / benzodiazepines, opiates, magic mushrooms, anabolic steroids, solvents, cannabis, alcohol and tobacco. Participants also answered a number of demographic questions (age, sex, location, occupation and education) and

*Address correspondence to this author at the Newcastle University, UK; Tel: +44 191222 7562; Fax: +44 191222 7520;

E-mail: Jacqui.rodgers@ncl.ac.uk questions relating to their participation (such as how they found out about the study).

\section{RESULTS}

An association was found between the lifetime use of ecstasy and self-reported difficulties in long-term prospective memory for some ecstasy users. Separate analysis of participants who had accessed our research via an ecstasy-related bulletin board indicated that for this group there was no association between long-term prospective memory and use of ecstasy. Further analyses revealed that the association between ecstasy and PMQ-LT was markedly reduced when nicotine and cannabis were included as covariates.

\section{DISCUSSION}

Here we demonstrated that cigarette smoking is associated with more memory problems in Ecstasy polydrug users. Given the high frequency of tobacco smokers who also use ecstasy and the finding here that suggests that the use of both substances may work additively to confer greater vulnerability, more work needs to be undertaken to explore the psychobiological effects of tobacco/ecstasy co-use. For instance, in one study Ecstasy users had significantly higher cortisol levels during tobacco abstinence, than an equivalent group of abstaining smokers who were not MDMA users [7, 8]. The differences between the data from the bulletin board and non-bulletin board participants reported here are intriguing and clearly warrant further investigation, including a more in-depth exploration of user characteristics from different website addresses and the complex relationship between beliefs, performance and self reports of functioning. This needs to be supported by studies which compare those immersed in the drug culture (i.e. our bulletin board participants) with those users who are not, on objective measures of functioning. 


\section{CONCLUSIONS}

The disclosure of prospective memory deficits amongst ecstasy users appears to be influenced by numerous factors.

Two novel factors identified were participation in an online ecstasy related bulletin board, and nicotine dependency.

\section{REFERENCES}

Rodgers J, Buchanan T, Scholey AB, Heffernan TM, Ling J, Parrott AC. Differential effects of ecstasy and cannabis on self-reports of memory ability: a web-based study. Hum Psychopharmacol 2001; 16: 619-25.

[2] Rodgers J, Buchanan, T, Scholey, AB, Heffernan TM, Ling J, Parrott AC. Patterns of drug use and the influence of gender on self-reports of memory ability in ecstasy users: a web based study. J Psychopharmacol 2003; 17: 389-96.

[3] Rodgers J, Buchanan T, Pearson C, et al. Differential experiences of the psychobiological sequelae of ecstasy use: quantitative and qualitative data from an internet study. J Psychopharmacol 2006; 20 : 437-46.

[4] Reips U-D. The Web experiment method: advantages, disadvantages, and solutions. In Birnbaum MH, Ed. Psychological Experiments on the Internet San Diego: Academic Press 2000; pp 69-117.

[5] Hannon R, Adams P, Harrington S, Fries-Dias C, Gibson MT Effects of brain injury and age on prospective memory self-rating and performance. Rehabil Psychol 1995; 40: 289-97.

[6] Parrott AC. Human research on MDMA (3, 4-methylenedioxymethamphetamine) neurotoxicity: cognitive and behavioral indices of change. Neuropsychobiology 2000; 42: 17-24.

[7] Parrott AC, Margetson JK, Kissling C, Thome J. Ecstasy, cigarettes and inverse pleasure: nicotine use and abstinence symptoms in recreational Ecstasy/MDMA users. J Psychopharmacol 2005; 19: a27.

[8] Parrott AC. Cortisol and MDMA (3, 4-methylenedioxymethamphetamine): neurohormonal aspects of bioenergetic stress in Ecstasy users. Neuropsychobiology 2009; 60: 148-58.

(C) Rodgers et al.; Licensee Bentham Open.

This is an open access article licensed under the terms of the Creative Commons Attribution Non-Commercial License (http://creativecommons.org/licenses/ by-nc/3.0/) which permits unrestricted, non-commercial use, distribution and reproduction in any medium, provided the work is properly cited. 